Article

\title{
Estimating the COVID-19 Death Toll by Considering the Time-Dependent Effects of Various Pandemic Restrictions
}

\author{
Hoang Pham \\ Department of Industrial and Systems Engineering, Rutgers University, Piscataway, NJ 08854, USA; \\ hopham@soe.rutgers.edu
}

Received: 19 August 2020; Accepted: 17 September 2020; Published: 20 September 2020

\begin{abstract}
COVID-19, known as Coronavirus disease 2019, is caused by a coronavirus called SARS-CoV-2. As coronavirus restrictions ease and cause changes to social and business activities around the world, and in the United States in particular, including social distancing, reopening states, reopening schools, and the face mask mandates, COVID-19 outbreaks are on the rise in many states across the United States and several other countries around the world. The United States recorded more than 1.9 million new infections in July, which is nearly 36 percent of the more than 5.4 million cases reported nationwide since the pandemic began, including more than 170,000 deaths from the disease, according to data from Johns Hopkins University as of 16 August 2020. In April 2020, the author of this paper presented a model to estimate the number of deaths related to COVID-19, which assumed that there would be no significant change in the COVID-19 restrictions and guidelines in the coming days. This paper, which presents the evolved version of the previous model published in April, discusses a new explicit mathematical model that considers the time-dependent effects of various pandemic restrictions and changes related to COVID-19, such as reopening states, social distancing, reopening schools, and face mask mandates in communities, along with a set of selected indicators, including the COVID-19 recovered cases and daily new cases. We analyzed and compared the modeling results to two recent models based on several model selection criteria. The model could predict the death toll related to the COVID-19 virus in the United States and worldwide based on the data available from Worldometer. The results show the proposed model fit the data significantly better for the United States and worldwide COVID-19 data that were available on 16 August 2020. The results show very encouraging predictability that reflected the time-dependent effects of various pandemic restrictions for the proposed model. The proposed model predicted that the total number of U.S. deaths could reach 208,375 by 1 October 2020, with a possible range of approximately 199,265 to 217,480 deaths based on data available on 16 August 2020. The model also projected that the death toll could reach 233,840 by 1 November 2020, with a possible range of 220,170 to 247,500 American deaths. The modeling result could serve as a baseline to help decision-makers to create a scientific framework to quantify their guidelines related to COVID-19 affairs. The model predicted that the death toll worldwide related to COVID-19 virus could reach 977,625 by 1 October 2020, with a possible range of approximately 910,820 to 1,044,430 deaths worldwide based on data available on 16 August 2020. It also predicted that the global death toll would reach nearly 1,131,000 by 1 November 2020, with a possible range of $1,030,765$ to $1,231,175$ deaths. The proposed model also predicted that the global death toll could reach 1.47 million deaths worldwide as a result of the SARS CoV-2 coronavirus that causes COVID-19. We plan to apply or refine the proposed model in the near future to further study the COVID-19 death tolls for India and Brazil, where the two countries currently have the second and third highest total COVID-19 cases after the United States.
\end{abstract}

Keywords: COVID-19 modeling; pandemic restrictions; S-shaped curve; death toll estimation; time-dependent effects 


\section{Introduction}

Recently, Pham [1] presented a model to estimate the COVID-19 death toll, assuming that there was no significant change of the pandemic restrictions and guidelines in the coming days. COVID-19 is a new disease that arose in December 2019 and it has quickly spread throughout the world [2,3]. There are more than 14.8 million cases reported and nearly 770,000 deaths worldwide related to the COVID-19 pandemic, according to data from Worldometer as of 15 August 2020 [4,5].

In general, it is difficult to track the ongoing coronavirus outbreaks when people are not aware of whether they are infected by the virus unless everyone is being tested. This will need a comprehensive national strategy and mandates in order to get the ongoing COVID-19 virus spread under control. With the current situation in the United States where not all the states in the country are strictly applying the same mandates and restrictions, such as social distancing, reopening states, face mask mandates, and reopening schools, some researchers are concerned that the number of infected cases will likely increase. In July, for example, there were more than 1.9 million new infections, which was nearly $36 \%$ of the total COVID-19 cases reported in the United States. According to some medical experts, it is best to apply social distancing and face mask guidelines, which can significantly reduce the spread of the virus [4,6]. Chin et al. [7] recently studied the detection of SARS-CoV 2 in various environmental conditions, including temperatures and objects. Pham and Pham [8] developed a logistic dependent model to study the presence of breast cancer based on some biomarkers.

Many researchers have recently developed models and approaches to determine guidelines and procedures for social distancing and healthcare practice [9-12], the case fatality rate [13-15], disease transmission [16,17], and disease detection in different environments [7]. Pham [1] developed a model to estimate the number of deaths in the United States using a logistic function. However, the model did not consider the changes in any of the COVID-19 restrictions. Pham [18] recently presented a model taking into account the changes of some restrictions based on an S-shaped curve. The results seem to be more optimistic and rapidly stable on the right tail. There are many studies on population growth based on various S-shaped models in the literature [19-22].

This paper presents a new explicit model with time-dependent effects of various COVID-19-related restrictions (i.e., reopening states, social distancing, reopening the community) and face mask mandates, as well as a set of selected indicators, including the recovered cases and daily new cases. We compared the proposed model to two recent models to predict the number of deaths in the United States and worldwide based on several model selection criteria. The results show that the new model fit the data significantly better. Sections 2 and 3 discuss the modeling analysis and results based on the COVID-19 death data from the Worldometer database, respectively. Section 4 discusses the findings and provides concluding remarks.

\section{Model Development}

This section discusses a new mathematical model that considers the time-dependent effects of various restrictions and changes related to COVID-19, such as reopening states, social distancing, reopening schools, and face mask mandates in the United States, along with a set of selected indicators, including the total number of cases and the death toll. It is reasonable to assume that these changes in the restrictions and to the guidelines can lead to an increase in the coronavirus cases and the death toll. In addition to the model considerations in Section 2.1 of Pham [1], which we will not repeat here, in this study, we also take into account the time-dependent effects of various restrictions and changes, along with a set of selected indicators, including the recovered cases and daily cases related to COVID-19. In this paper, we propose the following generalized ordinary differential equation model:

$$
\frac{\partial p(t)}{\partial t}=\gamma_{x}(t) b(t) p(t)(a(t)-p(t))
$$

where: 
$a(t) \quad$ is the total death toll plus the introduced death toll due to the changes of various pandemic restrictions by the time $t$

$b(t) \quad$ is the time - dependent death rate per unit by the time $t$

$p(t) \quad$ is the total number of deaths by the time $t$ with respect to $x$

$x \quad$ is a set of indicators (i.e., recovered cases, daily new cases, etc.)

$\gamma_{x}(t)$ is the time - dependent effects impacting the number of deaths due to the changes in $x$ by the time $t$.

The explicit expression of the function $p(t)$ can be obtained by solving the above differential equation (Equation (1)) for any given functions $a(t)$ and $b(t)$. Although it is often difficult to obtain a closed-form solution for $p(t)$, fortunately, with the help of MATLAB or R software, we can obtain the numerical solution for $p(t)$. In this study, we aimed to specifically propose a new explicit mathematical model that can predict the total number of deaths as a function of time $t, p(t)$, as follows:

$$
p(t)=\gamma_{x}(t) \frac{a+d\left(1-e^{-\alpha t}\right)}{1+\left(\frac{c}{\beta+e^{b t}}\right)},
$$

where $\gamma_{x}(t)$ represents an empirical estimated value based on $x$ as a function of time $t$ that reflects the time-dependent effects of recent changes in the pandemic restrictions; $p(t)$ is the death toll as a function of time $t$ based on $x ; a, b, c, d, \alpha$, and $\beta$ are the unknown constant parameters; $p(0)=\frac{a}{1+\frac{c}{\beta+1}}$ is the initial solution for the function $p(t)$ at the time $t=0$.

We now wish to determine the daily death toll, $r(t)$, which is given as:

$$
r(t)=\frac{\partial p(t)}{\partial t}
$$

The daily death toll, $r(t)$, can be obtained from Equation (2) as follows:

$$
r(t)=\gamma_{x}(t) \frac{a b c e^{b t}+\alpha d e^{-\alpha t}\left(\beta+e^{b t}+c\right)\left(\beta+e^{b t}\right)+b c d e^{b t}\left(1-e^{-\alpha t}\right)}{\left(\beta+e^{b t}+c\right)^{2}} .
$$

The parameters $d$ and $\alpha$ can reflect the new outbreaks of the COVID-19 cases due to various changes in the restrictions and mandates in the community. We can estimate the model parameters $a, b, c, d, \alpha$, and $\beta$ using the least-squares method. Table 1 summarizes the proposed model and recent models for predicting the total number of deaths $p(t)$ and the daily death toll $r(t)$. In Section 3 , we compare the results of the analysis of the proposed model to those of two existing models based on some selection criteria, namely, the MSE, AIC, BIC, PC, PIC, PRR, and PP (see Table A2 in Appendix B,

\begin{tabular}{|c|c|c|}
\hline Model & Total Death Toll $p(t)$ & Daily Death Toll $r(t)$ \\
\hline $\begin{array}{c}\text { Model } 1 \\
\text { [1] }\end{array}$ & $p(t)=\frac{a}{1+\left(\frac{c}{\beta+e^{b t}}\right)}$ & $r(t)=\frac{a b c e^{b t}}{\left[\left(\beta+e^{b t}\right)+c\right]^{2}}$ \\
\hline $\begin{array}{l}\text { Model } 2 \\
\text { [18] }\end{array}$ & $p(t)=\frac{a(1+d t)}{1+\left(\frac{c}{\beta+e^{b t}}\right)}$ & $\begin{aligned} r(t) & =\frac{a d\left(\beta+e^{b t}\right)}{\left(\beta+e^{b t}+c\right)} \\
+ & \frac{(1+d t)\left(a b c e^{b t}\right)}{\left(\beta+e^{b t}+c\right)^{2}}\end{aligned}$ \\
\hline $\begin{array}{c}\text { Model } 3 \\
\text { (new model) }\end{array}$ & $p(t)=\gamma_{x}(t) \frac{a+d\left(1-e^{-\alpha t}\right)}{1+\left(\frac{c}{\beta+e^{b t}}\right)}$ & $\begin{array}{l}r(t)=\gamma_{x}(t) \frac{a b c e^{b t}+b c d e^{b t}\left(1-e^{-\alpha t}\right)}{\left(\beta+e^{b t}+c\right)^{2}} \\
+\gamma_{x}(t) \frac{\alpha d e^{-\alpha t}\left(\beta+e^{b t}+c\right)\left(\beta+e^{b t}\right)}{\left(\beta+e^{b t}+c\right)^{2}}\end{array}$ \\
\hline
\end{tabular}
and their abbreviations are given in Section 4).

Table 1. The total and daily death toll functions of the proposed and recent models. 


\section{Modeling Results}

We now discuss the modeling results based on the COVID-19 death data from the Worldometer database [5] for the United States and worldwide. Worldometer contains detailed global COVID-19 data consisting of various variables, such as daily deaths, total deaths, recovered cases, and daily cases.

\subsection{Modeling Analysis for the United States}

We now show the death toll and daily deaths predictions for the United States based on the data available, which consisted of data for 170 days from 29 February 2020 to 16 August 2020. This is shown in Table A1 (in Appendix A), as well as along the "Day" axis in Figures 1-5, which is labeled as day 1 to day 270. Figures 1-3 show the data and predictions for the total number of deaths, daily deaths, and daily number of infected COVID-19 cases over time for the United States, respectively. Using the least-squares method, we estimated the model parameters and compared their results based on various model selection criteria, as shown in Table A2 in Appendix B. Table 2 shows the results of all three models and their corresponding rankings based on the model selection criteria.

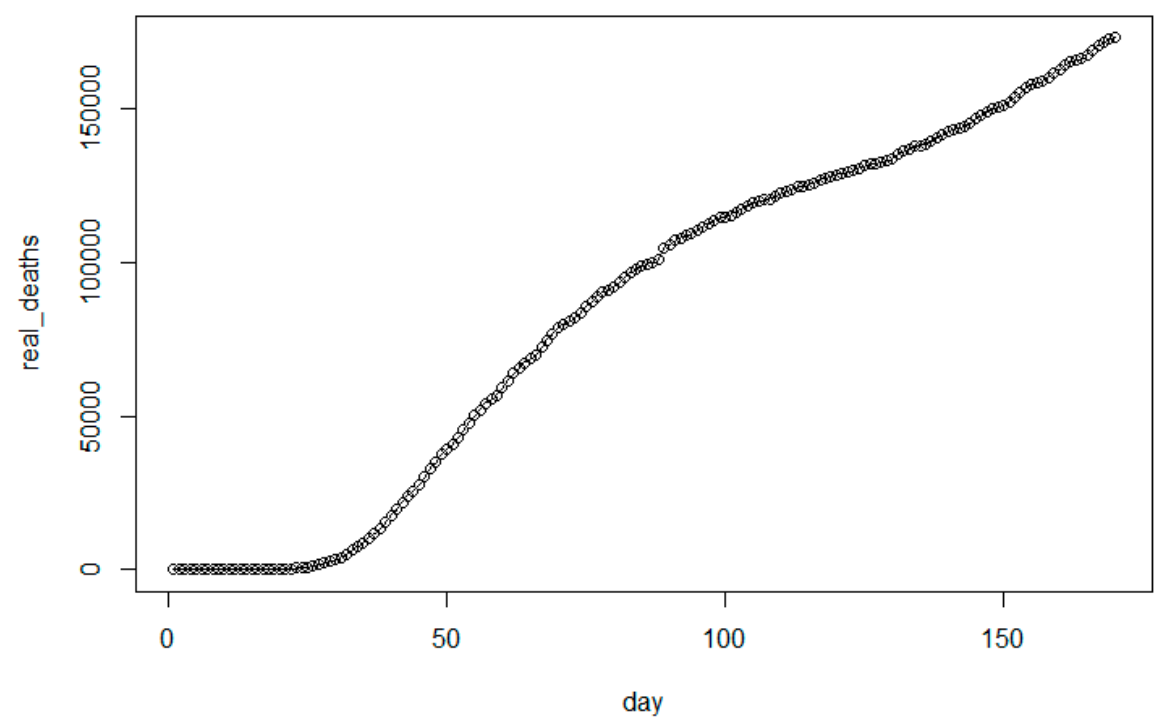

Figure 1. Cumulative number of deaths over time for the United States.

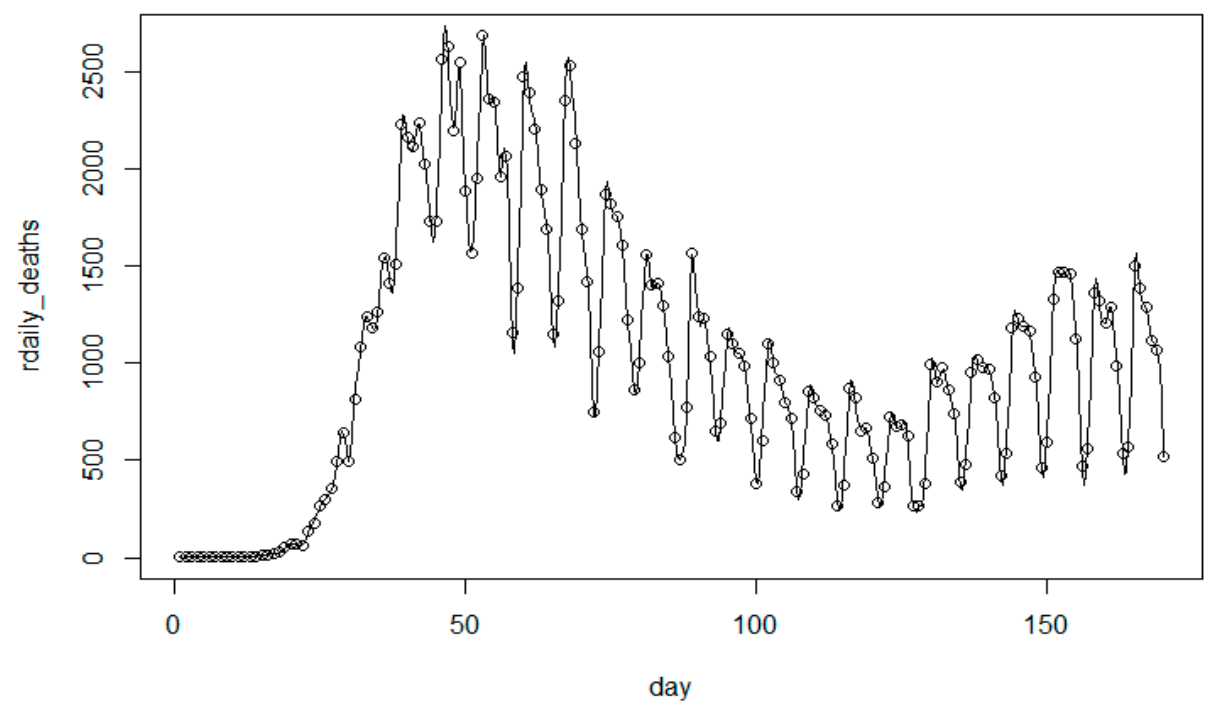

Figure 2. Daily number of deaths over time for the United States. 


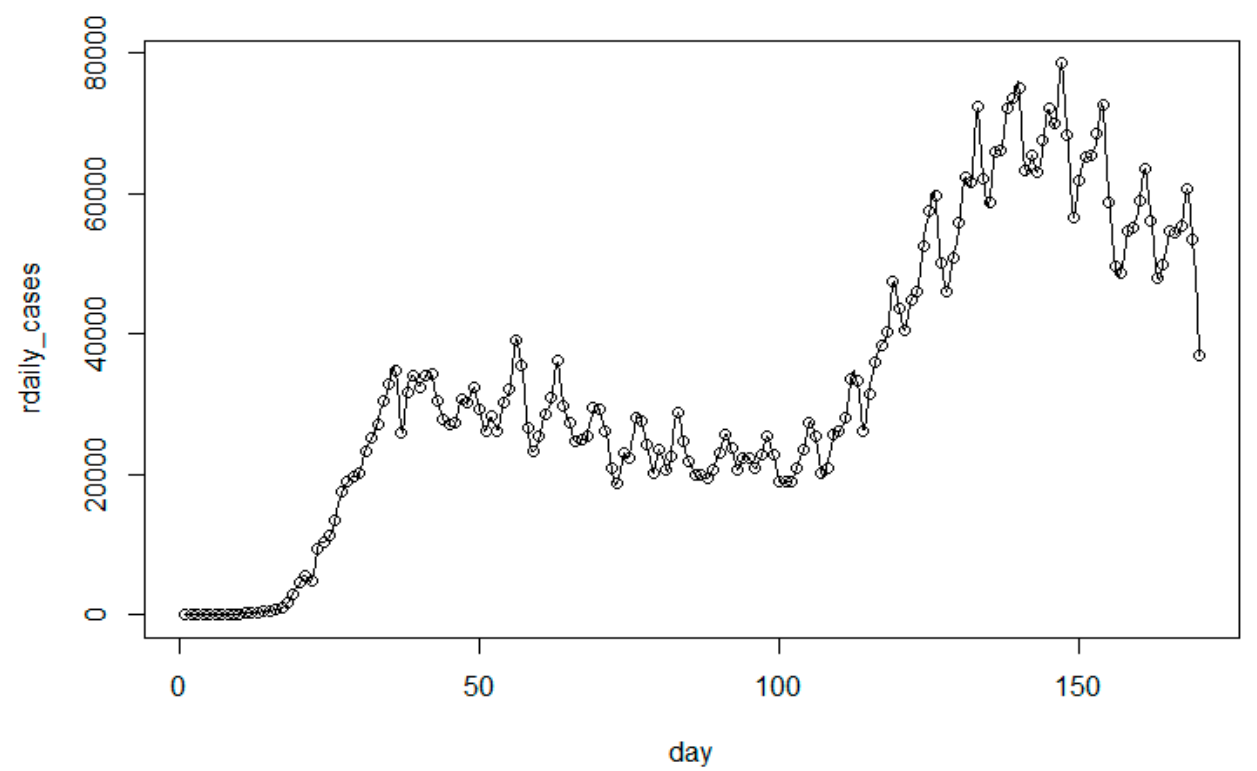

Figure 3. Daily number of infected cases over time for the United States.

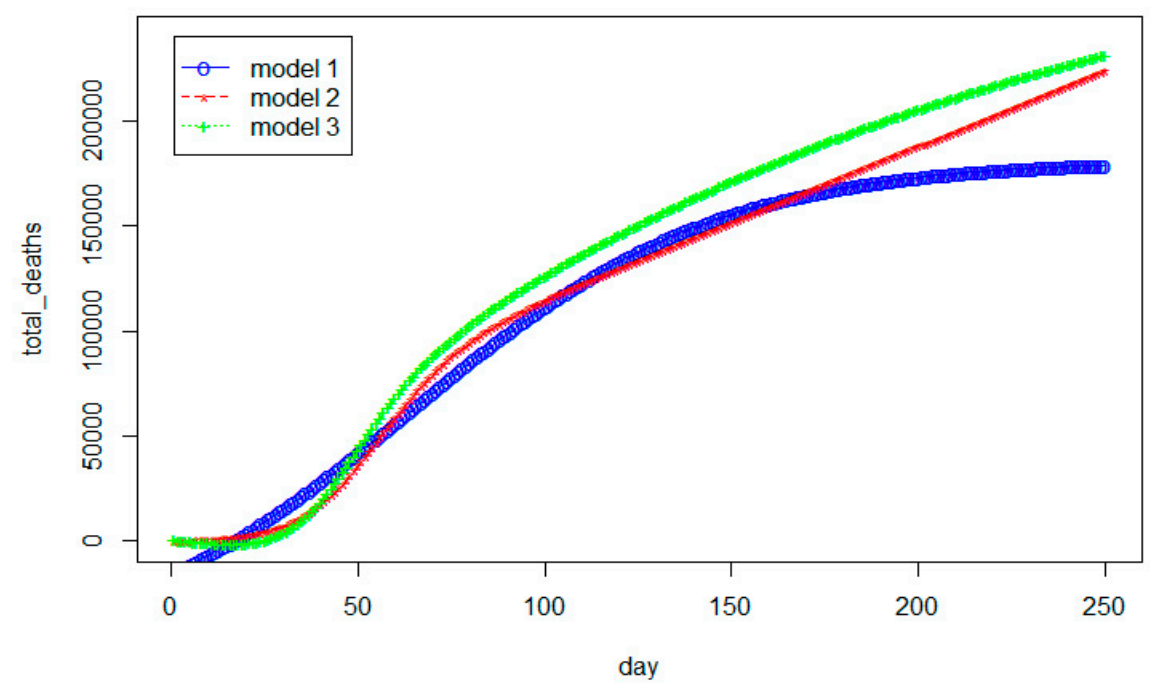

Figure 4. The estimated cumulative number of deaths over time for the United States.

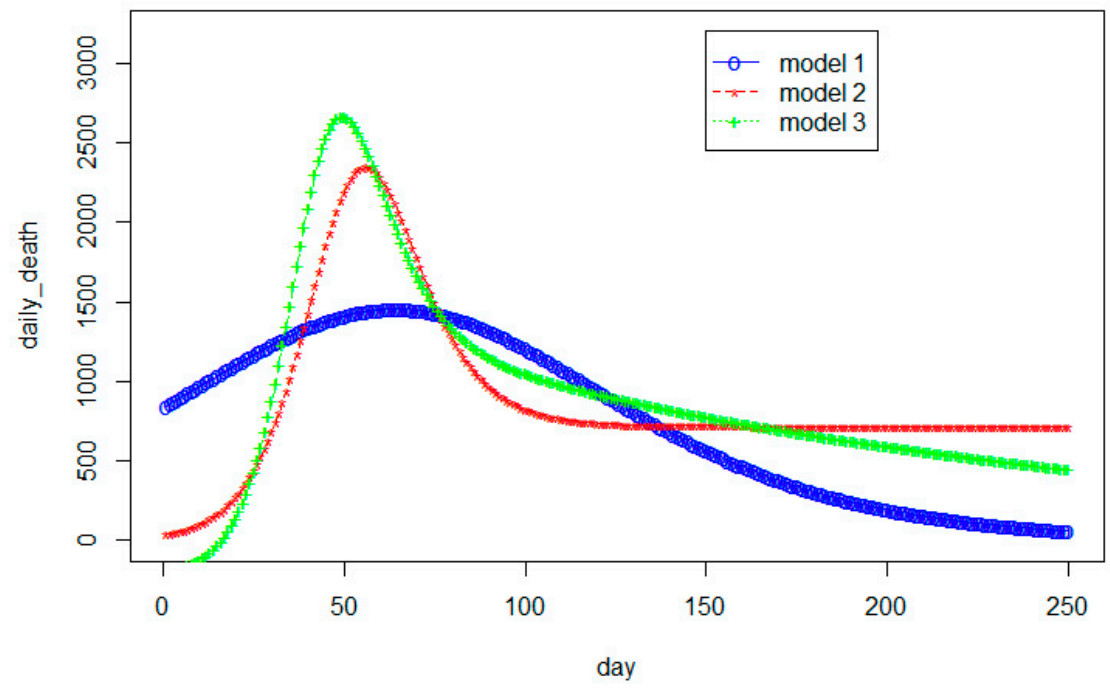

Figure 5. The estimated daily number of deaths over time for the United States. 
Table 2. Model comparison and ranking results using the model selection criteria based on the available data for the United States.

\begin{tabular}{|c|c|c|c|}
\hline \multirow[b]{2}{*}{ Selection Criteria } & Model 1 & Model 2 & \multirow{2}{*}{$\begin{array}{l}\text { New Model (Model 3) } \\
p(t)=\underset{\sim}{\gamma_{x}}(t) \frac{a+d\left(1-e^{-\alpha t}\right)}{1+\left(\frac{c}{\beta+e^{b t}}\right)}\end{array}$} \\
\hline & $p(t)=\frac{a}{1+\left(\frac{c}{\beta+e^{b t}}\right)}$ & $p(t)=\frac{a(1+d t)}{1+\left(\frac{c}{\beta+e^{b t}}\right)}$ & \\
\hline MSE (ranking) & $45602771(3)$ & $6014847(2)$ & $5185574(1)$ \\
\hline AIC (ranking) & $3002.0(3)$ & $2658.6(2)$ & $2634.3(1)$ \\
\hline BIC (ranking) & $3014.5(3)$ & $2674.3(2)$ & $2653.1(1)$ \\
\hline PC (ranking) & $1465.8(3)$ & $1290.5(2)$ & $1271.1(1)$ \\
\hline PIC (ranking) & $7570059990(3)$ & $992449703(2)$ & $850434102(1)$ \\
\hline PRR (ranking) & $31.2(2)$ & $25.4(1)$ & $72.0(3)$ \\
\hline PP (ranking) & $433739555(3)$ & $415378.8(1)$ & $935026.6(2)$ \\
\hline
\end{tabular}

AIC: Akaike's information criterion, BIC: Bayesian information criterion, MSE: mean squares error, PC: Pham's criterion, PIC: Pham's information criterion, PP: predictive power, PRR: predictive risk ratio.

The results in Table 2 show that the new model (model 3) fit the COVID-19 data available on 16 August 2020 significantly better when compared to the other two models based on most of the model selection criteria, namely, MSE, AIC, BIC, PC, and PIC, for the United States. In other words, when comparing all the models tested based on the selection criteria, we found that the new model had the smallest MSE, AIC, BIC, PC, and PIC values. However, model 2 provided the best fit based on the criteria PRR and PP. It is worth noting that in this application, the two criteria BIC and PC provided the same conclusion regarding selecting the best model. Although we would expect these two criteria (BIC and PC) to provide the same conclusion regarding the model selection, it is not necessary due to their different penalty terms. Figures 4 and 5 describe the projection of the total death toll and the daily number of people who have died of COVID-19, respectively, for the United States based on the data available on 16 August 2020. It should be noted that for model 1 [1], the prediction of the death toll for the United States was much lower due to the model's assumption that there was no change in the pandemic guidelines and restrictions in the weeks after April 2020. While model 2 predicted that the daily deaths are expected to remain relatively stable through October and November, model 3 predicted that the daily deaths are expected to decrease slightly through October and November.

The new model predicted that the total number of United States deaths could reach 208,375 by 1 October 2020, with a possible range from approximately 199,265 to 217,480 deaths based on the United States COVID-19 data available on 16 August 2020. The model also projected that the number of American deaths could reach 233,840 by 1 November 2020, with a possible range from 220,170 to 247,500 deaths. The modeling result can serve as a baseline to help decision-makers provide a scientific way to quantify their guidelines related to COVID-19 affairs.

\subsection{Worldwide Modeling Analysis}

Similarly, we obtained the worldwide modeling results based on the data available, which consisted of data for 207 days from 23 January 2020 to 16 August 2020. Figures 6-8 show the worldwide data on the total number of deaths, daily deaths, and daily number of infected COVID-19 cases, respectively. Table 3 shows the worldwide results of all three models and their corresponding ranking based on model selection criteria. The results show that the new model fit the data significantly better when compared to the other two models based on the MSE, AIC, BIC, PC, and PIC selection criteria. Model 2 still provided the best fit based on both the PRR and PP criteria for the worldwide data. 


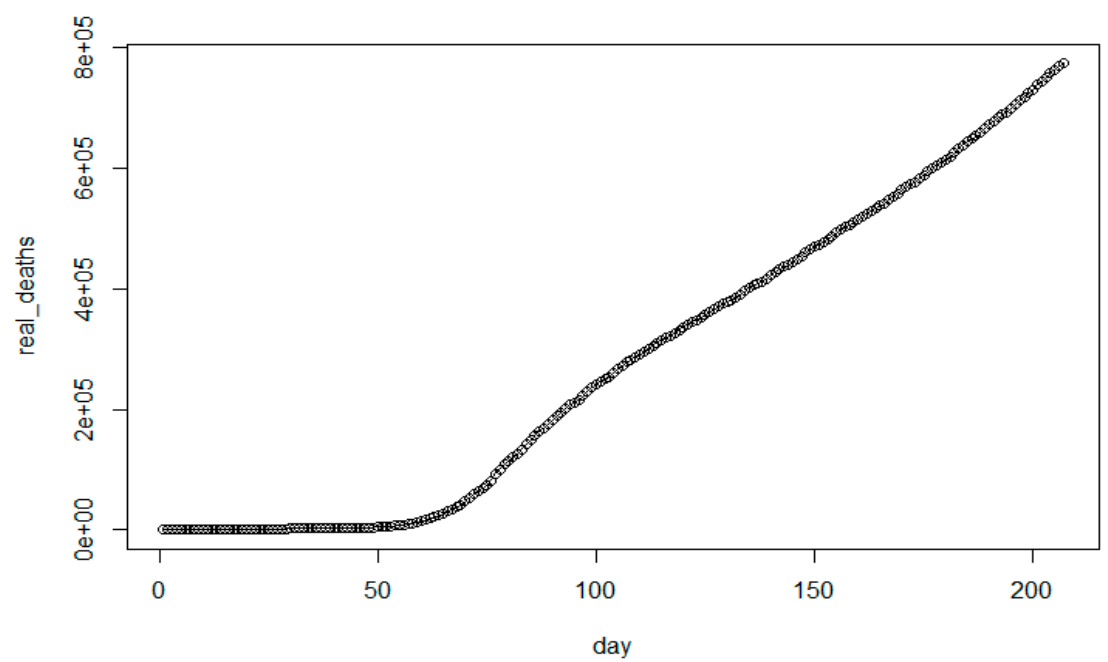

Figure 6. Worldwide cumulative number of deaths over time.

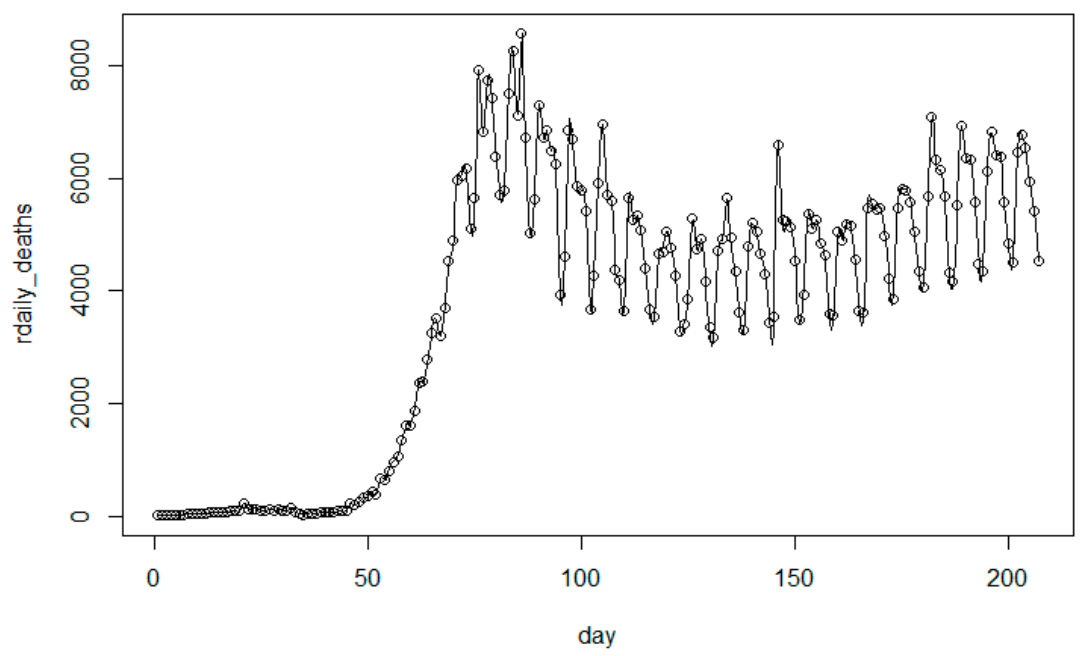

Figure 7. Worldwide daily number of deaths over time.

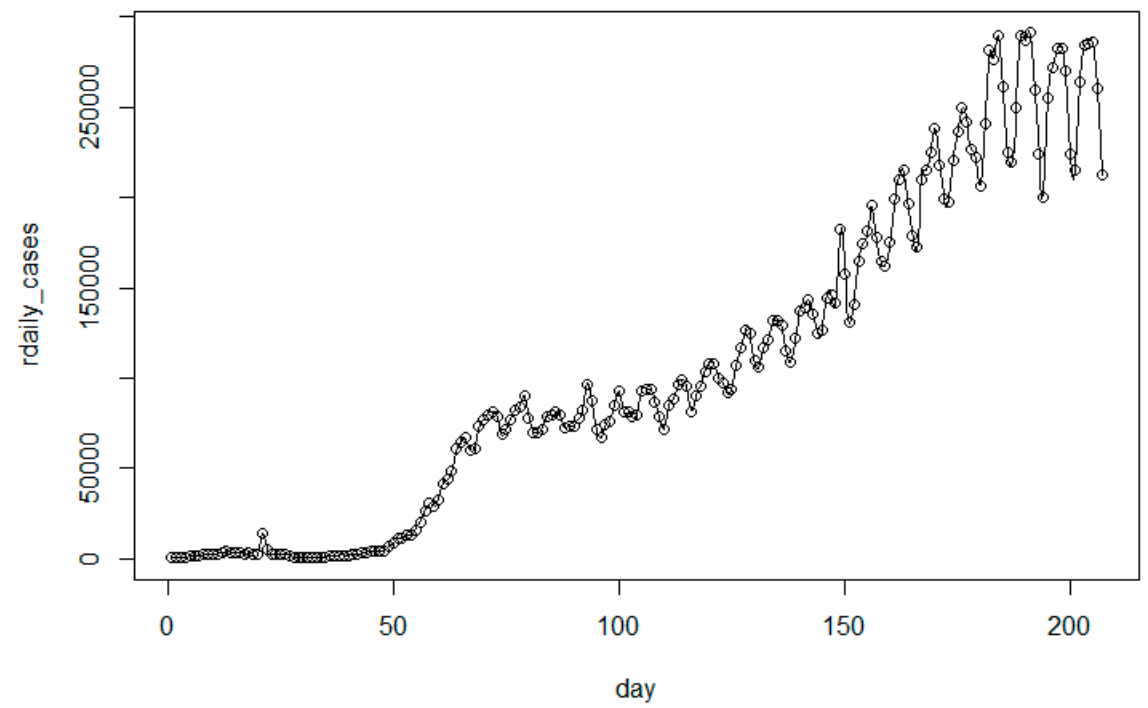

Figure 8. Worldwide daily number of infected cases over time. 
Table 3. Model comparison and ranking results using model selection criteria based on the available worldwide data.

\begin{tabular}{cccc}
\hline Model 1 & Model 2 & New Model (Model 3) \\
Selection Criteria & $\boldsymbol{p}(\boldsymbol{t})=\frac{a}{1+\left(\frac{c}{\beta+e^{b t}}\right)}$ & $\boldsymbol{p}(\boldsymbol{t})=\frac{a(1+d t)}{1+\left(\frac{c}{\beta+e^{b t}}\right)}$ & $\boldsymbol{p}(\boldsymbol{t})=\underset{\sim}{\gamma_{x}(t) \frac{a+d\left(1-e^{-\alpha t}\right)}{1+\left(\frac{c}{\beta+e^{b t}}\right)}}$ \\
\hline MSE (ranking) & $4806104858(3)$ & $455263766(2)$ & $278915137(1)$ \\
AIC (ranking) & $4618.6(3)$ & $4131.8(2)$ & $4031.3(1)$ \\
BIC (ranking) & $4632.0(3)$ & $4148.4(2)$ & $4051.3(1)$ \\
PC (ranking) & $2264.8(3)$ & $2016.2(2)$ & $1957.6(1)$ \\
PIC (ranking) & $975639286196(3)$ & $91963280768(2)$ & $56061942563(1)$ \\
PRR (ranking) & $94.9(2)$ & $21.4(1)$ & $158.9(3)$ \\
PP (ranking) & $7682.6(2)$ & $162.6(1)$ & $1572213(3)$ \\
\hline
\end{tabular}

The proposed model predicted that the total number of worldwide COVID-19 deaths could reach 977,625 by 1 October 2020, with a possible range of approximately 910,820 to $1,044,430$ global deaths based on data available on 16 August 2020. The model also predicted the global death toll to reach nearly $1,131,000$ by 1 November 2020, with a possible range of 1,030,765 to 1,231,175 deaths. The proposed model also predicted that the global COVID-19 death toll could reach 1.47 million deaths as a result of the SARS CoV-2 coronavirus that causes COVID-19. Figures 9 and 10 show the predictions of the total number of deaths and the daily death toll from COVID-19 around the world, respectively.

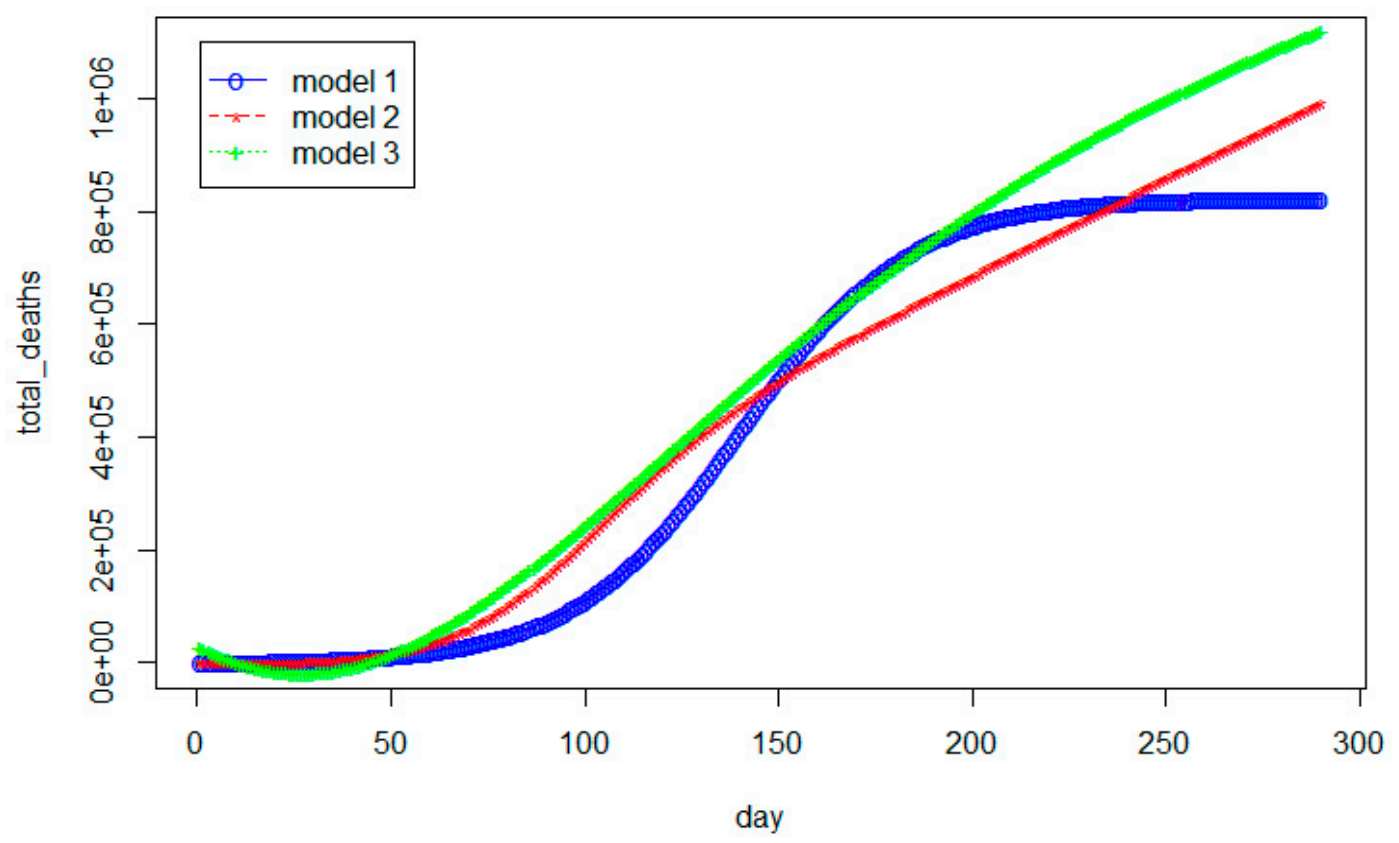

Figure 9. The estimated worldwide cumulative number of deaths over time. 


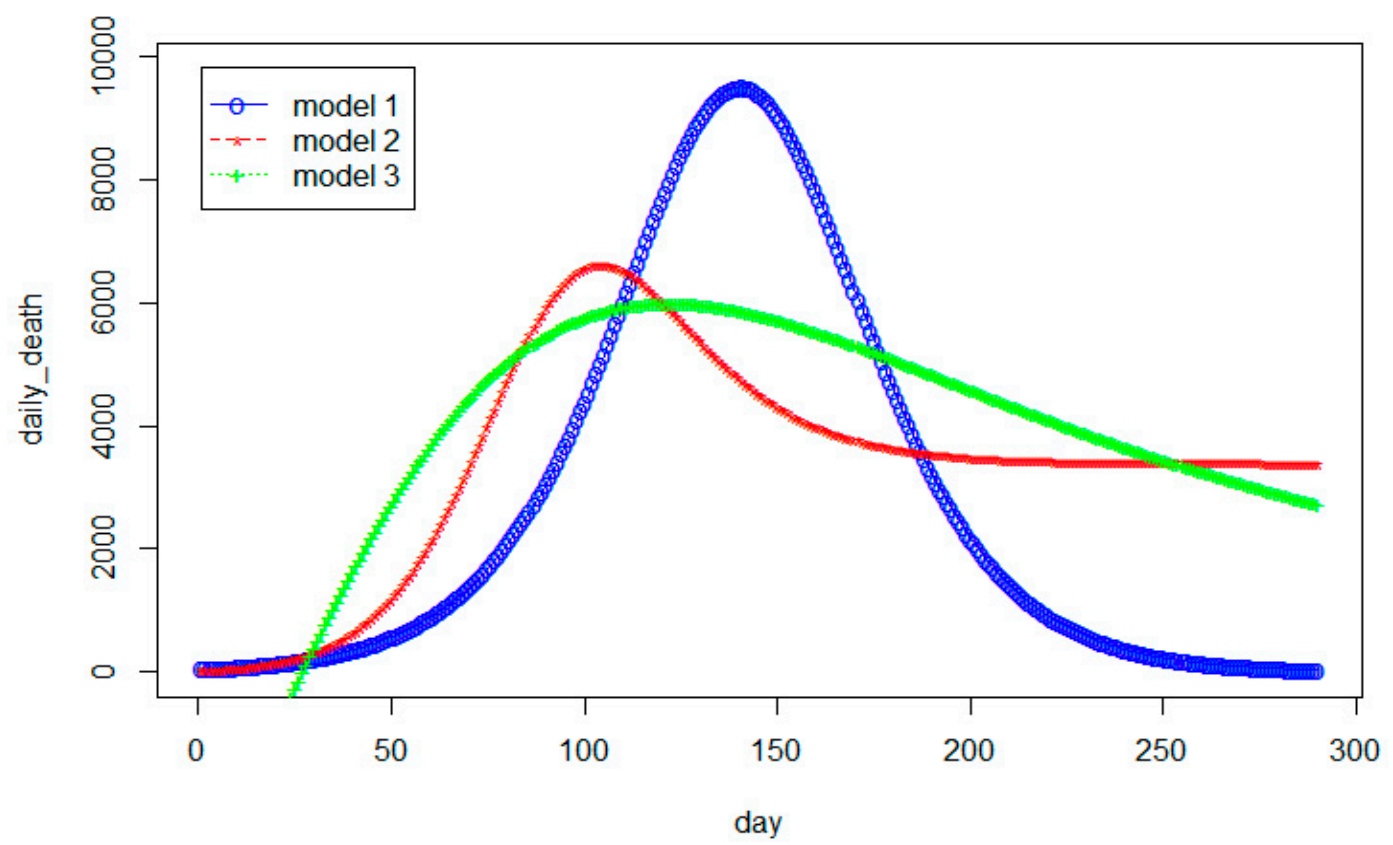

Figure 10. The estimated worldwide daily number of deaths over time.

\section{Conclusions}

This paper presents an explicit mathematical model that considers the time-dependent effects of various COVID-19-related restrictions and changes, such as reopening states, social distancing, reopening schools, and face mask mandates of various communities, as well as a set of selected indicators, such as the COVID-19 recovered cases and daily new cases in the United States. The model predicted the total deaths and the daily death toll related to the COVID-19 virus for the United States. We also applied the model to predict the worldwide death tolls. The modeling result can serve as a baseline to help policymakers by providing them with a scientific way to quantify their guidelines related to COVID-19 affairs. In the near future, we plan to apply the proposed model to analyze the COVID-19 death data for India and Brazil, where the two countries currently have the second and third highest total COVID-19 cases after the United States.

Funding: This research received no external funding.

Conflicts of Interest: The author confirms that there is no conflict of interest to declare for this publication.

\section{Abbreviations}

$\begin{array}{ll}\text { SSE } & \text { Sum of squared error } \\ \text { MSE } & \text { Mean squared error } \\ \text { AIC } & \text { Akaike's information criterion } \\ \text { BIC } & \text { Bayesian information criterion } \\ \text { PC } & \text { Pham's criterion } \\ \text { PIC } & \text { Pham's information criterion } \\ \text { PP } & \text { Predictive power } \\ \text { PRR } & \text { Predictive ratio-risk }\end{array}$




\section{Appendix A}

Table A1. U.S. death data [5] from 29 February 2020 to 16 August 2020.

\begin{tabular}{|c|c|c|c|c|c|}
\hline Date & $\begin{array}{c}\text { Cumulative } \\
\text { Number of Deaths }\end{array}$ & Date & $\begin{array}{c}\text { Cumulative } \\
\text { Number of Deaths }\end{array}$ & Date & $\begin{array}{c}\text { Cumulative } \\
\text { Number of Deaths }\end{array}$ \\
\hline $2 / 29$ & 1 & $4 / 26$ & 55,412 & $6 / 22$ & 125,155 \\
\hline $3 / 1$ & 1 & $4 / 27$ & 56,795 & $6 / 23$ & 126,026 \\
\hline $3 / 2$ & 6 & $4 / 28$ & 59,265 & $6 / 24$ & 126,845 \\
\hline $3 / 3$ & 9 & $4 / 29$ & 61,655 & $6 / 25$ & 127,498 \\
\hline $3 / 4$ & 11 & $4 / 30$ & 63,856 & $6 / 26$ & 128,161 \\
\hline $3 / 5$ & 12 & $5 / 1$ & 65,753 & $6 / 27$ & 128,673 \\
\hline $3 / 6$ & 15 & $5 / 2$ & 67,444 & $6 / 28$ & 128,958 \\
\hline $3 / 7$ & 19 & $5 / 3$ & 68,597 & $6 / 29$ & 129,324 \\
\hline $3 / 8$ & 22 & $5 / 4$ & 69,921 & $6 / 30$ & 130,050 \\
\hline $3 / 9$ & 26 & $5 / 5$ & 72,271 & $7 / 1$ & 130,726 \\
\hline $3 / 10$ & 30 & $5 / 6$ & 74,799 & $7 / 2$ & 131,413 \\
\hline $3 / 11$ & 38 & $5 / 7$ & 76,928 & $7 / 3$ & 132,039 \\
\hline $3 / 12$ & 41 & $5 / 8$ & 78,615 & $7 / 4$ & 132,305 \\
\hline $3 / 13$ & 48 & $5 / 9$ & 80,037 & $7 / 5$ & 132,568 \\
\hline $3 / 14$ & 58 & $5 / 10$ & 80,787 & $7 / 6$ & 132,946 \\
\hline $3 / 15$ & 73 & $5 / 11$ & 81,847 & $7 / 7$ & 133,939 \\
\hline $3 / 16$ & 95 & $5 / 12$ & 83,718 & $7 / 8$ & 135,140 \\
\hline $3 / 17$ & 121 & $5 / 13$ & 85,540 & $7 / 9$ & 136,114 \\
\hline $3 / 18$ & 171 & $5 / 14$ & 87,293 & $7 / 10$ & 136,975 \\
\hline $3 / 19$ & 239 & $5 / 15$ & 89,104 & $7 / 11$ & 137,717 \\
\hline $3 / 20$ & 309 & $5 / 16$ & 90,324 & $7 / 12$ & 138,102 \\
\hline $3 / 21$ & 374 & $5 / 17$ & 91,189 & $7 / 13$ & 138,577 \\
\hline $3 / 22$ & 509 & $5 / 18$ & 92,193 & $7 / 14$ & 139,529 \\
\hline $3 / 23$ & 689 & $5 / 19$ & 93,750 & $7 / 15$ & 140,550 \\
\hline $3 / 24$ & 957 & $5 / 20$ & 95,155 & $7 / 16$ & 141,529 \\
\hline $3 / 25$ & 1260 & $5 / 21$ & 96,569 & $7 / 17$ & 142,495 \\
\hline $3 / 26$ & 1614 & $5 / 22$ & 97,868 & $7 / 18$ & 143,317 \\
\hline $3 / 27$ & 2110 & $5 / 23$ & 98,904 & $7 / 19$ & 143,736 \\
\hline $3 / 28$ & 2754 & $5 / 24$ & 99,519 & $7 / 20$ & 144,274 \\
\hline $3 / 29$ & 3251 & $5 / 25$ & 100,025 & $7 / 21$ & 145,459 \\
\hline $3 / 30$ & 4066 & $5 / 26$ & 100,800 & $7 / 22$ & 146,689 \\
\hline $3 / 31$ & 5151 & $5 / 27$ & 104,635 & $7 / 23$ & 147,881 \\
\hline $4 / 1$ & 6394 & $5 / 28$ & 105,873 & $7 / 24$ & 149,043 \\
\hline $4 / 2$ & 7576 & $5 / 29$ & 107,106 & $7 / 25$ & 149,968 \\
\hline $4 / 3$ & 8839 & $5 / 30$ & 108,139 & $7 / 26$ & 150,509 \\
\hline $4 / 4$ & 10,384 & $5 / 31$ & 108,790 & $7 / 27$ & 151,106 \\
\hline $4 / 5$ & 11,793 & $6 / 1$ & 109,485 & $7 / 28$ & 152,436 \\
\hline $4 / 6$ & 13,298 & $6 / 2$ & 110,632 & $7 / 29$ & 153,901 \\
\hline $4 / 7$ & 15,526 & $6 / 3$ & 111,736 & $7 / 30$ & 155,366 \\
\hline $4 / 8$ & 17,691 & $6 / 4$ & 112,786 & $7 / 31$ & 156,826 \\
\hline $4 / 9$ & 19,802 & $6 / 5$ & 113,773 & $8 / 1$ & 157,949 \\
\hline $4 / 10$ & 22,038 & $6 / 6$ & 114,490 & $8 / 2$ & 158,416 \\
\hline $4 / 11$ & 24,062 & $6 / 7$ & 114,874 & $8 / 3$ & 158,978 \\
\hline $4 / 12$ & 25,789 & $6 / 8$ & 115,472 & $8 / 4$ & 160,338 \\
\hline $4 / 13$ & 27,515 & $6 / 9$ & 116,576 & $8 / 5$ & 161,657 \\
\hline $4 / 14$ & 30,081 & $6 / 10$ & 117,574 & $8 / 6$ & 162,860 \\
\hline $4 / 15$ & 32,712 & $6 / 11$ & 118,490 & $8 / 7$ & 164,152 \\
\hline $4 / 16$ & 34,905 & $6 / 12$ & 119,290 & $8 / 8$ & 165,138 \\
\hline $4 / 17$ & 37,448 & $6 / 13$ & 120,004 & $8 / 9$ & 165,672 \\
\hline $4 / 18$ & 39,331 & $6 / 14$ & 120,340 & $8 / 10$ & 166,241 \\
\hline $4 / 19$ & 40,901 & $6 / 15$ & 120,772 & $8 / 11$ & 167,745 \\
\hline $4 / 20$ & 42,853 & $6 / 16$ & 121,630 & $8 / 12$ & 169,131 \\
\hline $4 / 21$ & 45,536 & $6 / 17$ & 122,449 & $8 / 13$ & 170,415 \\
\hline $4 / 22$ & 47,894 & $6 / 18$ & 123,205 & $8 / 14$ & 171,535 \\
\hline $4 / 23$ & 50,234 & $6 / 19$ & 123,934 & $8 / 15$ & 172,606 \\
\hline $4 / 24$ & 52,191 & $6 / 20$ & 124,516 & $8 / 16$ & 173,128 \\
\hline $4 / 25$ & 54,256 & $6 / 21$ & 124,786 & & \\
\hline
\end{tabular}




\section{Appendix B}

Table A2. Model selection criteria [23].

\begin{tabular}{|c|c|c|c|}
\hline No. & Criteria & Formula & Brief Description \\
\hline 1 & $\begin{array}{l}\text { Sum of square } \\
\text { error (SSE) }\end{array}$ & $\mathrm{SSE}=\sum_{i=1}^{n}\left(y_{i}-\hat{y}_{i}\right)^{2}$ & $\begin{array}{l}\text { Measures the total deviations between the } \\
\text { estimated values and the actual data. }\end{array}$ \\
\hline 2 & MSE [21] & $\mathrm{MSE}=\frac{\sum_{i=1}^{n}\left(y_{i}-\hat{y}_{i}\right)^{2}}{n-k}$ & $\begin{array}{l}\text { Measures the difference between the } \\
\text { estimated values and the actual data. }\end{array}$ \\
\hline 3 & AIC [24] & $\mathrm{AIC}=-2 \log (\mathrm{L})+2 \mathrm{k}$ & $\begin{array}{l}\text { Measures the goodness of the fit after } \\
\text { considering the penalty of adding } \\
\text { more parameters. }\end{array}$ \\
\hline 4 & BIC [25] & $\mathrm{BIC}=-2 \log (\mathrm{L})+k \log (n)$ & $\begin{array}{l}\text { Same as the AIC but the penalty term also } \\
\text { depends on the sample size. }\end{array}$ \\
\hline 5 & PIC [22] & $\begin{array}{c}\text { PIC }=\text { SSE }+k\left(\frac{n-1}{n-k}\right) \\
\text { where SSE }=\sum_{i=1}^{n}\left(y_{i}-\hat{y}_{i}\right)^{2}\end{array}$ & $\begin{array}{l}\text { Takes into account a larger penalty when } \\
\text { there is too small of a sample but too many } \\
\text { parameters in the model. }\end{array}$ \\
\hline 6 & $\operatorname{PRR}[21]$ & $\mathrm{PRR}=\sum_{i=1}^{n}\left(\frac{\hat{m}\left(t_{i}\right)-y_{i}}{\hat{m}\left(t_{i}\right)}\right)^{2}$ & $\begin{array}{l}\text { Measures the distance of the model } \\
\text { estimates from the actual data against the } \\
\text { model estimate. }\end{array}$ \\
\hline 7 & PP [21] & $\mathrm{PP}=\sum_{i=1}^{n}\left(\frac{\hat{n}\left(t_{i}\right)-y_{i}}{y_{i}}\right)^{2}$ & $\begin{array}{c}\text { Measures the distance of the model } \\
\text { estimates from the actual data against the } \\
\text { actual data. }\end{array}$ \\
\hline 8 & PC [1] & $\begin{array}{c}\mathrm{PC}=\left(\frac{n-k}{2}\right) \log \left(\frac{\mathrm{SSE}}{n}\right)+k\left(\frac{n-1}{n-k}\right) \\
\text { where SSE }=\sum_{i=1}^{n}\left(y_{i}-\hat{y}_{i}\right)^{2}\end{array}$ & $\begin{array}{l}\text { Slightly increases the penalty each time } \\
\text { parameters are added to the model when } \\
\text { there is too small of a sample. }\end{array}$ \\
\hline
\end{tabular}

\section{References}

1. Pham, H. On Estimating the Number of Deaths Related to Covid-19. Mathematics 2020, 8, 655. [CrossRef]

2. Patch.com. Available online: https://patch.com/new-jersey/oceancity/nj-coronavirus-update-gov-murphyconsiders-curfew-31-new-cases (accessed on 15 August 2020).

3. Rothan, H.A.; Byrareddy, S.N. The epidemiology and pathogenesis of coronavirus disease (COVID-19) outbreak. J. Autoimmun. 2020, 109, 102433. [CrossRef] [PubMed]

4. CNN. 2020. Available online: https://www.cnn.com/2020/08/02/health/us-coronavirus-sunday/index.html (accessed on 15 August 2020).

5. Worldometers. 2020. Available online: https://www.worldometers.info/coronavirus/?utm_campaign= homeAdvegas1?\#countries (accessed on 17 August 2020).

6. CDC. Centers for Disease Control and Prevention. 2020. Available online: https://www.cdc.gov/countries (accessed on 15 August 2020).

7. Chin, A.W.H.; Chu, J.T.S.; Perera, M.R.A.; Hui, K.P.Y.; Yen, H.-L.; Chan, M.C.W.; Peiris, M.; Poon, L.L.M. Stability of SARS-CoV-2 in different environmental conditions. Lancet Microbe 2020, 1. [CrossRef]

8. Pham, H.; Pham, D.H. A novel generalized logistic dependent model to predict the presence of breast cancer based on biomarkers. Concurr. Comput. Pract. Exp. 2020, 32, e5467. [CrossRef]

9. Dong, E.; Du, H.; Gardner, L. An interactive web-based dashboard to track COVID-19 in real time. Lancet Infect. Dis. 2020, 20, 533-534. [CrossRef]

10. Prem, K.; Liu, Y.; Russell, T.W.; Kucharski, A.J.; Eggo, R.M.; Davies, N.; Jit, M.; Klepac, P.; Flasche, S.; Clifford, S.; et al. The effect of control strategies to reduce social mixing on outcomes of the COVID-19 epidemic in Wuhan, China: A modelling study. Lancet Public Health 2020, 5, e261-e270. [CrossRef]

11. De Brouwer, E.; Raimondi, D.; Moreau, Y. Modeling the COVID-19 outbreaks and the effectiveness of the containment measures adopted across countries. medRxiv 2020. [CrossRef]

12. Sebastiani, G.; Massa, M.; Riboli, E. Covid-19 epidemic in Italy: Evolution, projections and impact of government measures. Eur. J. Epidemiol. 2020, 35, 341-345. [CrossRef] [PubMed] 
13. Onder, G.; Rezza, G.; Brusaferro, S. Case-Fatality Rate and Characteristics of Patients Dying in Relation to COVID-19 in Italy. JAMA 2020, 323, 1775-1776. [CrossRef] [PubMed]

14. Rajgor, D.D.; Lee, M.H.; Archuleta, S.; Bagdasarian, N.; Quek, S.C. The many estimates of the COVID-19 case fatality rate. Lancet Infect. Dis. 2020, 20, 776-777. [CrossRef]

15. Battegay, M.; Kuehl, R.; Tschudin-Sutter, S.; Hirsch, H.H.; Widmer, A.F.; Neher, R.A. 2019-novel Coronavirus (2019-nCoV): Estimating the case fatality rate-A word of caution. Swiss Med. Wkly. 2020, 150, w20203. [CrossRef] [PubMed]

16. Kucharski, A.J.; Russell, T.W.; Diamond, C.; Liu, Y.; Edmunds, J.; Funk, S.; Eggo, R.M.; Sun, F.; Jit, M.; Munday, J.D.; et al. Early dynamics of transmission and control of COVID-19: A mathematical modelling study. Lancet Infect. Dis. 2020, 20, 553-558. [CrossRef]

17. Law, G.R.; Feltbower, R.G.; Taylor, J.C.; Parslow, R.C.; Gilthorpe, M.S.; Boyle, P.; McKinney, P.A. What do epidemiologists mean by 'population mixing'? Pediatric Blood Cancer 2008, 51, 155-160. [CrossRef] [PubMed]

18. Pham, H. Predictive Modeling on the Number of Covid-19 Death Toll in the United States Considering the Effects of Coronavirus-Related Changes and Covid-19 Recovered Cases. Int. J. Math. Eng. Manag. Sci. 2020, 5. [CrossRef]

19. Verhulst, P. Recherches mathe matiques sur la loi d'accroissement de la population. Nouv. Mem. L'academie R. Sci. Belles-Lett. Brux. 1845, 18, 1-41.

20. Pham, H.; Pham, D.H.; Pham, H. A New Mathematical Logistic Model and Its Applications. Int. J. Inf. Manag. Sci 2014, 25, 79-99.

21. Pham, H. System Software Reliability; Springer: London, UK, 2006.

22. Pham, H. A New Criterion for Model Selection. Mathematics 2019, 7, 1215. [CrossRef]

23. Pham, H. Predictive Modeling on the Number of Covid-19 Death Toll in the United States Considering the Effects of Coronavirus-Related Changes and Covid-19 Recovered Cases. medRxiv 2020. [CrossRef]

24. Akaike, H. Information Theory and an Extension of the Maximum Likelihood Principle. In Second International Symposium on Information Theory; Petrov, B.N., Caski, F.L., Eds.; Akademiai Kiado: Budapest, Hungary, 1973; pp. 267-281.

25. Schwarz, G. Estimating the dimension of a model. Ann. Stat. 1978, 6, 461-464. [CrossRef]

(C) 2020 by the author. Licensee MDPI, Basel, Switzerland. This article is an open access article distributed under the terms and conditions of the Creative Commons Attribution (CC BY) license (http://creativecommons.org/licenses/by/4.0/). 